\title{
Proceeding
}

Supplementary Issue: Summer Conferences of Sports Science. Costa Blanca Sports Science Events, 25-26 September 2020. Alicante, Spain.

\section{A 30-min test applied to stand-up paddleboarding: A pilot study}

\author{
HENRIQUE P. NEIVA1,2 4 , LUÍS B. FAíl'1,2, DANIEL A. MARINHO1,2 \\ ${ }^{1}$ Department of Sport Sciences, University of Beira Interior, Covilhã, Portugal \\ ${ }^{2}$ Research Center in Sports Sciences, Health and Human Development (CIDESD), Portugal
}

\begin{abstract}
The popularity of stand-up paddle boarding (SUP) has grown in recent decades, but little is known about SUP training and performance. The current pilot study aimed to analyse performance, biomechanical, and physiological variables during a 30-min all-out test. After a 10-min warm-up, one experienced male paddler(28years) performed a maximal 30-min SUP test wearing a Garmin Fénix 3 HR (Taipei, Taiwan) device. A total distance of $3.70 \mathrm{~km}$ was performed, with a mean speed of $2.19 \pm 0.32 \mathrm{~m} . \mathrm{s}^{-1}, 52.63 \pm 2.62$ strokes per minute, and $2.39 \pm 0.39 \mathrm{~m}$ per stroke. The mean heart rate $(\mathrm{HR})$ was $160.78 \pm 3.18 \mathrm{bpm}$, which corresponded to $85.34 \%$ (Cl95\%: 83.69, 85.69\%) of maximal HR, and it was maintained throughout the 30 min test (coefficient of variation [CV]: 1.98\%). The stroke rate was more stable throughout the test than the distance per stroke (CV: $4.98 \%$ vs. 16.20\%). Significant relationships were found between speed and distance per stroke $(r=-0.80, p<.001)$, but not between speed and stroke rate $(r=0.03, p=.75)$. The 30min test was found to represent intensity of around $85 \%$ of maximal HR. The speed was negatively correlated with the distance per stroke during the test, thus suggesting that decreased distance per stroke will increase the paddling speed at constant intensities.
\end{abstract}

Keywords: SUP; Performance; Biomechanics; Anaerobic threshold.

\section{Cite this article as:}

Neiva, H.P., Faíl, L.B. \& Marinho, D.A. (2020). A 30-min test applied to stand-up paddle boarding: A pilot study. Journal of Human Sport and Exercise, 15(4proc), S1387-S1393. doi:https://doi.org/10.14198/jhse.2020.15.Proc4.35

\footnotetext{
Corresponding author. Department of Sport Sciences, University of Beira Interior, Covilhã, Portugal. http://orcid.org/0000-0001$\underline{9283-312 X}$

E-mail: henriquepn@gmail.com

Abstract submitted to: Spring Conferences of Sports Science. Costa Blanca Sports Science Events, 19-20 June 2020. Alicante, Spain.

JOURNAL OF HUMAN SPORT \& EXERCISE ISSN 1988-5202

(c) Faculty of Education. University of Alicante

doi:10.14198/jhse.2020.15.Proc4.35
} 


\section{INTRODUCTION}

The stand-up paddle boarding (SUP) has been in clear development in recent years (Schram et al., 2016). This is a sport that is easily accessible and learned and, beyond competition purposes, it allows easy recreational aquatic activity and potentially causing health benefits in the short and long term (Schram et al., 2015). In this activity, the athlete paddles while standing on board larger than that of traditional surfing (Ruess et al., 2013a; Schram et al., 2015), providing better buoyancy, stability, and increasing power per stroke (Suari et al., 2018). The larger board also facilitates learning among beginners' paddlers of all ages (Ruess et al., 2013b; Schram et al., 2015). Referred to as a full-body workout by social media and internet magazines, SUP has been recently the subject of investigation.

Only recently, research has tried to understand physiological and biomechanical issues of SUP in recreational and competitive participants (e.g. Schram et al., 2017; Schram et al., 2019; Balikian et al., 2020). In general, SUP paddle stroke is characterized by a phase of entry of the paddle into the water, an impulse phase, where the paddle is pulled through the water, and finally, a phase of exit of the paddle from the water (Schram et al., 2015). Moreover, stroke kinematics was found to be different between experienced and inexperienced participants (Schram et al., 2019). Experienced paddlers rely less on the shoulder and minimum elbow range of motion, but employ more hip flexion (Schram et al., 2019). So, it seems clear that the stroke technique is different according to the athlete level and this could result in different physiological outcomes (CastañedaBabarro et al., 2020). Previous studies found improvement in aerobic and anaerobic fitness, multidirectional core strength assessments, and self-rated quality of life in physical and psychological domains after 6 weeks of SUP training (Schram et al., 2016b). In general, SUP athletes are characterized as having good balance, strength in trunk muscles, and well trained in aerobic fitness, as the aerobic metabolism is of great importance in different races (Schram et al., 2016a).

The efficiency of movement combined with aerobic power and anaerobic threshold are variables that can influence and predict performance in endurance sports (Costa et al., 2012). It is known that SUP mainly involves events from 4 to $20 \mathrm{~km}$ races or even longer. Therefore, it should be suggested that there is a great aerobic contribution during these races (Gastin, 2001). Thereby, SUP requires high levels of cardiorespiratory fitness, with aerobic capacity as a high standard for great competition results (Schram et al., 2017). The aerobic capacity of SUP athletes should be monitored and maximized during training, and this is only possible with an efficient training evaluation and exercise intensity prescription. Recently, the 30min test has been suggested as a good strategy to evaluate aerobic capacity in Paddlers (Balikian et al., 2020), but further analysis (i.e. biomechanical and physiological) should be performed. Quantifying movement patterns of this modality is important for coaches and athletes to develop specific programs (Cunniffe et al., 2009). Thus, the current pilot study aimed to analyse performance, biomechanical, and physiological variables during a 30 min all-out test. With this, we intend to better understand the behaviour of an experienced SUP athlete during this usual anaerobic threshold test, contributing to increased knowledge on the profile of these athletes.

\section{MATERIAL AND METHODS}

\section{Participant}

One male paddler, 28 years old, with 6 years as a paddler experience $(74 \mathrm{~kg}, 1.83 \mathrm{~m})$, was recruited to participate voluntarily in this pilot study. This athlete paddled at least 3 times per week in the last 6 months and was ranked in the national competition (mean volume higher than $10 \mathrm{~km}$ per week). The participant was without a history of back pain and was free from any physical and psychological impairments. He was informed of the benefits and risks of the investigation and signed an intuitionally approved informed consent 
document before participation in this study. This study was approved by the University Ethics Committee and All procedures were in accordance with the Helsinki Declaration regarding Human research.

\section{Procedures}

All procedures were performed in calm water, without current interference (outdoor temperature of $18^{\circ} \mathrm{C}$, with a wind of $\left.2.5 \mathrm{~km} \cdot \mathrm{h}^{-1}\right)$. A course was demarcated to allow the application of the test and the athlete used a board of $3.81 \mathrm{~m}$ in length. After arriving at the settings, height $(\mathrm{cm})$ was measured in the anthropometrical position from vertex to the floor with a digital stadiometer (SECA, 242, Hamburg, Germany), with precision within $1 \mathrm{~mm}$, and body mass was measured in the upright position with a digital weight scale (SECA 884, Hamburg, Germany) within $0.1 \mathrm{~kg}$. Then, the participant warmed-up for 5 min out of the water and then 10 min of specific warm-up with low intensity (i.e. rating of perceived exertion easy; heart rate $<120 \mathrm{bpm}$ ). After a specific warm-up, the athlete performed a maximum test for $30 \mathrm{~min}$. The athlete was allowed to alternate paddling on each side ad libitum and was instructed to complete the total distance as fast as possible. Time was recorded using a manual digital chronometer (S140, Seiko, Japan). Distance, physiological (heart rates), and biomechanical variables (stroke rate and distance per stroke) were analysed using Garmin Fénix $3 \mathrm{HR}$ (Taipei, Taiwan) device. These variables were recorded each $20 \mathrm{~s}$ and these values were used for further analysis. The predicted maximal heart rate (208 - $0.7 \times$ age) was estimated according to the procedures suggested elsewhere (Tanaka et al., 2001).

\section{Statistical analysis}

All data analysis used the Microsoft Office Excel 16 program and the Statistical Package of Social Science (version 22.0; SPSS, Chicago, IL, USA). The values of means, standard deviations, $95 \%$ confidence interval (Cl95\%), and the coefficient of variation (CV) were computed by standardized statistical methods. The Pearson Correlation Coefficient between speed, heart rate, stroke rate, and distance per stroke throughout the 30min test was determined to analyse relationships between performance, biomechanical, and physiological variables $(p<.05)$. These relationships were represented graphically for better interpretation of the obtained results.

\section{RESULTS}

The athlete performed the maximum SUP test with a mean velocity of $2.19 \pm 0.32{\mathrm{~m} . \mathrm{s}^{-1}}$ (CV: $14.45 \%$ ) covering a total distance of $3.70 \mathrm{~km}$. Stroke rate values recorded during the 30 min were $52.63 \pm 2.62$ strokes per minute, and $2.39 \pm 0.39 \mathrm{~m}$ distance was performed per stroke. The mean heart rate was $160.78 \pm 3.18$ bpm, which corresponded to approximately $85.34 \%$ (CI95\%: 83.69, 85.69\%) of predicted maximal heart rate. The athlete was able to maintain this percentage throughout the 30 min test ( $C V=1.98 \%)$. Additionally, the stroke rate was more stable throughout the test than the distance per stroke (CV: $4.98 \%$ vs. 16.20\%).

Table 1. Pearson's correlation coefficient $(r)$ and $p$-values of the performance, biomechanical and physiological variables recorded during the 30 min test.

\begin{tabular}{lcccccccc} 
& \multicolumn{2}{c}{ Speed } & \multicolumn{2}{c}{ Heart rate } & \multicolumn{2}{c}{ Stroke rate } & \multicolumn{2}{c}{ Distance per stroke } \\
\cline { 2 - 9 } & $r$ & $p$-value & $r$ & $p$-value & $r$ & $p$-value & $r$ & $p$-value \\
\cline { 2 - 9 } Speed & & & 0.05 & .618 & 0.03 & .750 & -0.80 & $<.001$ \\
Heart rate & 0.05 & .618 & & & 0.11 & .299 & -0.09 & .373 \\
Stroke rate & 0.03 & .750 & 0.11 & .299 & & & -0.37 & $<.001$ \\
Distance per stroke & -0.80 & $<.001$ & -0.09 & .373 & -0.37 & .000 & & \\
\hline
\end{tabular}


In Table 1 is presented the relationships between variables assessed. It was found a significant linear and negative relationship between speed and distance per stroke, clearly presented in Figure 1. As expected, distance per stroke was significantly correlated with stroke rate, but no other significant relationship was found between variables.

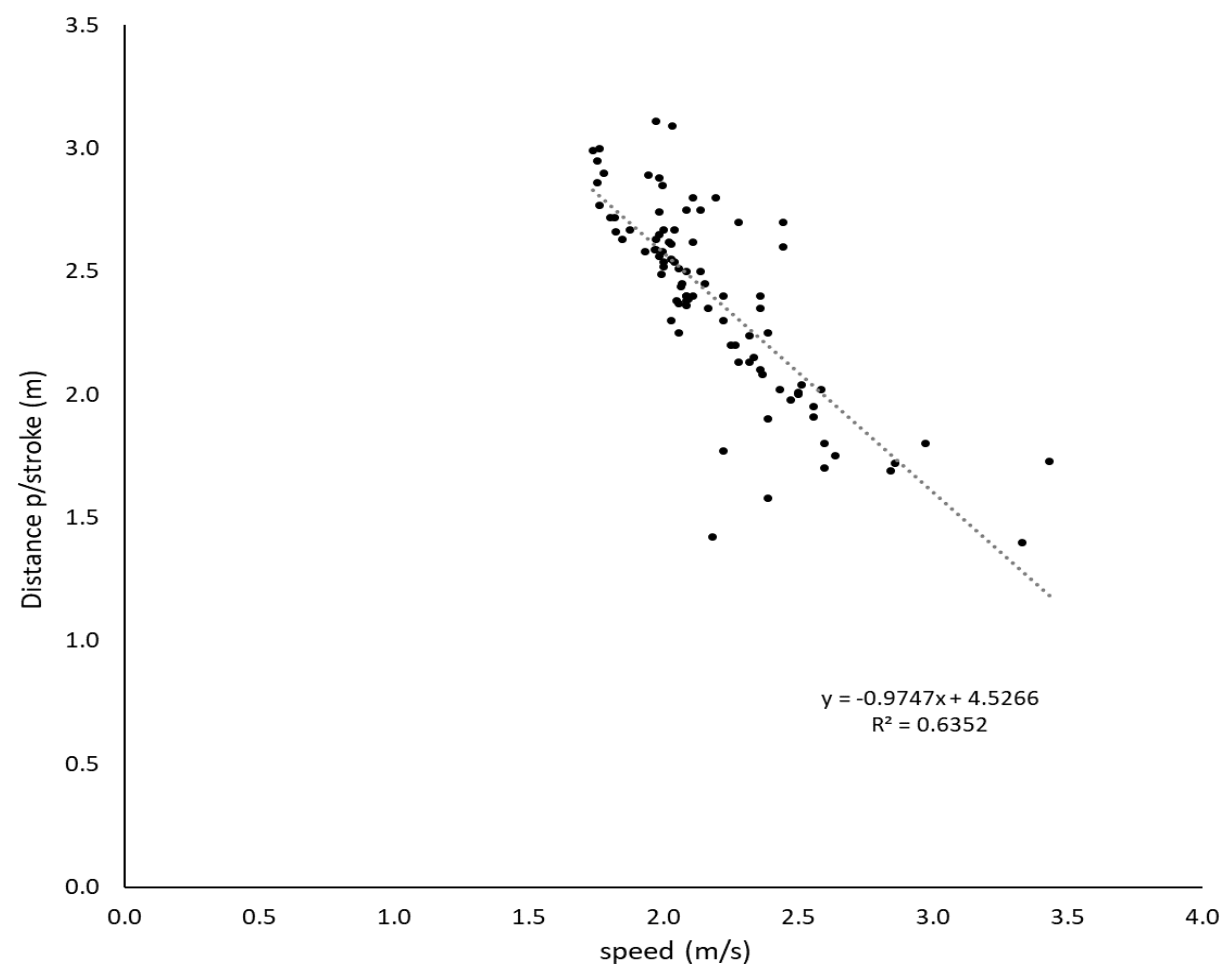

Figure 1. Relationships between speed and distance per stroke.

\section{DISCUSSION}

The present study aimed to analyse performance (speed), biomechanical (stroke rate, distance per stroke), and physiological (heart rate) variables during a 30 min all-out test of SUP. Significant negative relationships were found between speed and distance per stroke. In contrast, the correlation coefficient was not significant between velocity and stroke rate. It was also found that the stroke rate was more stable throughout the test than de distance per stroke. Moreover, the effort during the all-out test, expressed by the percentage of maximal heart rate, corresponded to vigorous aerobic activity, and the athlete was able to maintain this intensity constant throughout the test.

Until recently, information about the paddling technique for SUP and physiological demands of this sport was only available on social media or instructional videos and guidelines. Research started to focus on this emerging sport in the last ten years and some interesting findings were found, mainly in recreational athletes (e.g. Bancks and Shorter, 2018). Nowadays, there is an increasing interest in the long-term effects of SUP and investigations tried to improve and optimize training methodologies so that performance can be improved (e.g. Castañeda-Babarro et al., 2020). This way, some usual evaluations that have been used in other sports to monitor training loads have been started to be used in SUP (Balikian et al., 2020). We aimed to understand a little more about the application of the usual 30 min test, that has been used to evaluate anaerobic threshold and as a traditional aerobic training set. 
The current results showed that the speed was negatively correlated with the distance per stroke during the test, thus suggesting that decreased distance per stroke will increase the paddling speed at constant intensities, as found by Schram et al. (2015). Previous results showed that elite SUP athletes presented lower stroke length than recreational $(\sim 3 \%)$ or sedentary ( $7 \%)$ athletes, but this did not mean a worse stroke. The higher stroke rate with a shorter stroke is usually used by higher-level athletes, and it is related to a more powerful stroke (Schram et al., 2015). Together, powerful strokes with higher frequency were found to be more beneficial to overall performance (Schram et al., 2015). This was also verified in some other cyclic sports, such as swimming or rowing (Costa et al., 2012; Sealey et al., 2011).

Despite we did not found significant correlations between speed and stroke rate, the stroke rate was more stable during the test than the distance per stroke. This could also explain the heart rate that remained stable throughout the $30 \mathrm{~min}$ effort, reflecting the similar stroke rate used. Previous findings showed that a lower stroke rate (approximately 45 strokes per minute) was more efficient than a higher stroke rate (55 to 65 strokes per minute) (Castañeda-Babarro et al., 2020). These authors considered the higher cadences to be less effective because they can increase instability and consequently energy consumption (CastañedaBabarro et al, 2020). Therefore, as the stroke rate was maintained constant throughout the all-out test, it could be suggested that intensity and effort level was constant, as presented by the heart rate values. The fact that the wind was insignificant also helps to these results, otherwise, the effort level would change and heart rate accordingly (Castañeda-Babarro et al., 2020; Suari et al., 2018; Yukawa et al., 2015). So, despite higher-level athletes benefit from lower distance per stroke and more powerful strokes, this will require additional energy expenditure throughout the effort.

From a physiological standpoint, the use of a 30-minute continuous effort has been related and used as a method to assess aerobic capacity in other sports (Dekerle et al., 2002; Costa et al., 2012). This was also suggested as a valid and non-invasive approach to determine the anaerobic threshold in SUP athletes (Balikian et al., 2020). Our findings supported that a high-level SUP athlete is able to perform a 30-min allout test at a vigorous intensity, with little variation in heart rate. Nevertheless, data from the current study suggested a great variation in distance per stroke than the stroke rate. This could be resultant from external factors, such as wind or water currents (Castañeda-Babarro et al., 2020), but also because of some changes in technique and/or force applied in each stroke that could vary and influence distance per stroke. Regardless of the best method to attain higher performance (speed) - with higher or lower distance per stroke - it is important to pay attention to the movement performed. According to Schram et al. (2019), during the paddling movement (paddle entry and exit of the water) the athlete must increase the range of motion of the hip and decrease the range of movement of the shoulder for movement to be more efficient. Any change could be resultant from less efficient technique and therefore, changes in stroke mechanics (i.e. stroke rate, distance per stroke).

We should understand that the current study aimed to be a pilot study and therefore, we have to acknowledge several limitations. The single SUP athlete that participated in the current study could not be representative of all SUP athletes, but it gives us an idea of the biomechanical and physiological response during a 30-min all-out effort. Although it is difficult to obtain larger samples in elite sports and this case, in a new sport, further research should explore the physiological and biomechanical responses to different training sets and/or races. 


\section{CONCLUSIONS}

In summary, the results of the current study demonstrated that a 30-min all-out assessment corresponded to a vigorous aerobic activity that an experienced SUP athlete can maintain for all the duration of the test. The stroke rate was kept more constant than distance per stroke throughout the test and it was found a negative relationship between speed and distance per stroke. This study intended to be a step forward and contributing to increased knowledge about paddlers' physiological and biomechanical response to a long-term effort, usually related with endurance performances.

\section{ACKNOWLEDGEMENTS}

This work is supported by national funding through the Portuguese Foundation for Science and Technology, I.P., under project UID04045/2020.

\section{REFERENCES}

Balikian, P., Marinho, A. H., de Araujo, G. G., Prado, E. S., Mendes, E. V., \& Geraldes, A. A. R. (2020). Anaerobic Threshold in Stand-up Paddle: Comparison Between Direct and Alternative Methods. The Journal of Strength \& Conditioning Research. https://doi.org/10.1519/JSC.0000000000003718

Bancks, M., \& Shorter, K. (2018). Upper Body Kinematic Analysis of the Paddling Stroke in Female Recreational Stand-up Paddle Boarders. ISBS Proceedings Archive, 36(1), 406.

Castañeda-Babarro, A., Santos-Concejero, J., Viribay, A., Gutiérrez-Santamaría, B., \& Mielgo-Ayuso, J. (2020). The Effect of Different Cadence on Paddling Gross Efficiency and Economy in Stand-Up Paddle Boarding. International Journal of Environmental Research and Public Health, 17(13), 4893. https://doi.org/10.3390/ijerph17134893

Costa, M. J., Bragada, J. A., Marinho, D. A., Silva, A. J., \& Barbosa, T. M. (2012). Longitudinal interventions in elite swimming: a systematic review based on energetics, biomechanics, and performance. The Journal of Strength \& Conditioning Research, 26(7), 2006-2016. https://doi.org/10.1519/JSC.0b013e318257807f

Cunniffe, B., Proctor, W., Baker, J. S., \& Davies, B. (2009). An Evaluation of the Physiological Demands of Elite Rugby Union Using Global Positioning System Tracking Software. Journal of Strength and Conditioning Research, 23(4), 1195-1203. https://doi.org/10.1519/JSC.0b013e3181a3928b

Dekerle, J., Sidney, M., Hespel, J. M., \& Pelayo, P. (2002). Validity and reliability of critical speed, critical stroke rate, and anaerobic capacity in relation to front crawl swimming performances. International journal of sports medicine, 23(02), 93-98. https://doi.org/10.1055/s-2002-20125

Gastin, P. B. (2001). Energy system interaction and relative contribution during maximal exercise. Sports medicine, 31(10), 725-741. https://doi.org/10.2165/00007256-200131100-00003

Ruess, C., Kristen, K. H., Eckelt, M., Mally, F., Litzenberger, S., \& Sabo, A. (2013a); Activity of Trunk and Leg Muscles during Stand up Paddle Surfing. Procedia Engineering, 60, 57-61. https://doi.org/10.1016/j.proeng.2013.07.031

Ruess, C., Kristen, K. H., Eckelt, M., Mally, F., Litzenberger, S., \& Sabo, A. (2013b). Stand up Paddle Surfing-An Aerobic Workout and Balance Training. Procedia Engineering, 60, 62-66. https://doi.org/10.1016/..proeng.2013.07.032

Schram, B. L., Hing, W. A., Climstein, M., \& Furness, J. W. (2017). A Performance Analysis of a StandUp Paddle Board Marathon Race. Journal of Strength and Conditioning Research, 31(6), 1552-1556. https://doi.org/10.1519/JSC.0000000000001707 
Schram, B., Furness, J., Kemp-Smith, K., Sharp, J., Cristini, M., Harvie, D., ... \& Becker, M. (2019). A biomechanical analysis of the stand-up paddle board stroke: a comparative study. PeerJ, 7, e8006. https://doi.org/10.7717/peeri.8006

Schram, B., Hing, W., \& Climstein, M. (2015). Profiling the sport of stand-up paddle boarding. Journal of Sports Sciences, 34(10), 937-944. https://doi.org/10.1080/02640414.2015.1079331

Schram, B., Hing, W., \& Climstein, M. (2016a). Laboratory-and field-based assessment of maximal aerobic power of elite stand-up paddle-board athletes. International Journal of Sports Physiology and Performance, 11(1), 28-32. https://doi.org/10.1123/ijspp.2015-0076

Schram, B., Hing, W., \& Climstein, M. (2016b). The physiological, musculoskeletal and psychological effects of stand up paddle boarding. BMC Sports Science, Medicine and Rehabilitation, 8(1). https://doi.org/10.1186/s13102-016-0057-6

Sealey, R. M., Ness, K. F., \& Leicht, A. S. (2011). Effect of self-selected and induced slow and fast paddling on atroke kinematics during $1000 \mathrm{~m}$ outrigger canoeing ergometry. Journal of Sports Science \& Medicine, 10(1), 52-58.

Suari, Y., Schram, B., Ashkenazi, A., Gann-Perkal, H., Berger, L., Reznikov, M., ... Kodesh, E. (2018). The Effect of Environmental Conditions on the Physiological Response during a Stand-Up Paddle Surfing Session. Sports, 6(2), 25. https://doi.org/10.3390/sports6020025

Tanaka, H., Monahan, K. D., \& Seals, D. R. (2001). Age-predicted maximal heart rate revisited. Journal of the american college of cardiology, 37(1), 153-156. https://doi.org/10.1016/S07351097(00)01054-8

Yukawa, H., lino, M., \& Fujiwara, T. (2015). Estimation and Visualization of Paddling Effort for Stand Up Paddle Boarding with a Geographical Information System. Procedia Engineering, 112, 552-555. https://doi.org/10.1016/j.proeng.2015.07.243

\section{@) $\odot \Theta \Theta$}

This work is licensed under a Attribution-NonCommercial-NoDerivatives 4.0 International (CC BY-NC-ND 4.0). 